\title{
ADSORPTION ISOTHERM AND KINETIC STUDIES ONTO REMOVAL OF REACTIVE YELLOW -14 DYE BY USING IXORA COCCINEA LEAF POWDER
}

\author{
H. Revathi ${ }^{1, *}$, A. Kaviyarasu ${ }^{1}$, T. Murugan ${ }^{2}$, M. Dinesh Kumar ${ }^{1}$ \\ and R. Sharmila Devi ${ }^{1}$ \\ ${ }^{1}$ Department of Chemistry, Karpagam Academy of Higher Education, \\ Coimbatore-641 021, Tamil Nadu, India \\ ${ }^{2}$ Department of Chemistry, Adithya Institute of Technology, \\ Coimbatore-641 107, Tamil Nadu, India \\ *E-mail:catchreva@gmail.com
}

\begin{abstract}
Dyes are a complex organic compound which is used by various industries to color their products. These dyes enter the water which makes them polluted. Today, color removal from wastewater has been a matter of concern, both in the aesthetic sense and health point of view. Color removed from textile effluents on a continuous industrial scale has been given much attention in the last few years, not only because of its potential toxicity but also mainly due to its visibility problem. Ixora coccinea leaves have been used for the removal of Reactive Yellow-14 dye. The adsorption studies are undertaken in a systematic manner and effect of different parameters such as adsorbent dosage, agitation time, and $\mathrm{pH}$ of the aqueous solution on the removal of the dye is determined. pH results to be an interesting variable and dye removal decreases as $\mathrm{pH}$ increases. The adsorption-equilibrium was represented with Freundlich, Langmuir and Temkin isotherms. The adsorption process followed the first order kinetics. The results indicated that the dye, Reactive Yellow-14 strongly interacts with a Biomass-based adsorbent; the Ixora Coccinea leaf powder.

Keywords: Ixora Coccinea Leaf Powder (ICLP), Reactive Yellow-14 dye (RY-14), Adsorption Isotherm, Kinetics, Dye removal, Adsorption.
\end{abstract}

(C) RASĀYAN. All rights reserved

\section{INTRODUCTION}

Water is one of the important ecosystems for the existence of the biotic species. If we do not save the water properly it would lead to loss of biodiversity. Industrial and agricultural wastes highly pollute present water sources ${ }^{1}$. Dyes and pigments present in wastewater which are discharged from various industries like textile, paper, leather and paint ${ }^{2}$ are hazardous to human and pollute the environment.It is estimated that the textile and dyeing industry uses more than $7 \times 105$ Metric tons of dye per year ${ }^{3}$.

Dyes possess complex molecular structure and they are generally aromatic ${ }^{4}$, Dyes are highly colored polymers and low biodegradable in nature, dyes have many different and complicated molecular structures and difficult to treat ${ }^{5}$, the dyes are one of the important parts of the pollution problems as it is estimated that $50 \%$ of their amount is not fixed on fiber and remain finally in wastewater ${ }^{6}$. Before final disposal, the dye effluents should be treated to permissible limits ${ }^{7}$.Comparing to other industries the textile industry ranks first in using dyes ${ }^{8}$. Reactive dyes have been a great concern for protecting the water ecosystem because many azo dyes and the breakdown products have been found toxic to aquatic like, mutagenic/ carcinogenic and genotoxic effect and up to 50\% of reactive dyes are lost through hydrolysis during the dyeing process ${ }^{9}$. Reactive dyes are widely used in the textile industries and fibers through chemical combining ${ }^{10}$.

Adsorption techniques for wastewater treatment have become popular in recent years due to the removal of pollutants. Adsorption is used in the removal of pollution from the wastewater. Water pollution can be

Rasayan J. Chem., 11(4), 1415-1422(2018)

http://dx.doi.org/10.31788/RJC.2018.1143054

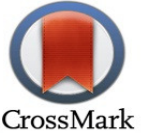


controlled by adsorption treatment ${ }^{6}$. Removal of dyes can be done through adsorption and it is one of the most economical and effective methods ${ }^{8}$ to treat wastewater.

Ixora Coccinea is commonly known as a jungle of geranium and red Ixora, is an evergreen shrub found throughout India ${ }^{11}$. Depending on the medical condition the flower, the leaves, roots, and the stems are used to treat the various ailments in the Indian traditional system of medicine, the Ayurveda, and also in various folk medicines.

Activated carbon is the most popular method used for adsorption process but the preparation of activated carbon and regeneration process are very costly.The popular techniques such as ion-exchange, Electrokinetic coagulation, electrochemical oxidation, membrane filtration, and photo-catalytic degradation process are expensive and are not applicable to large-scale treatments ${ }^{12}$.Hence we undertook an attempt to prepare low cost and easily available biomass material for the removal of dyes from waste water ${ }^{13}$.In this paper, an attempt to elucidate the potential of Ixora Coccinea leaf powder as biomass for the adsorption of Reactive Yellow dye-14 has been carried out. The effect of various parameters such as sorbent dose, contact time and $\mathrm{pH}$ was studied. The experimental data was further fitted to different isotherm models viz., Freundlich, Langmuir and Temkin ${ }^{14}$.

\section{EXPERIMENTAL}

The biomass (Ixora Coccinea leaves) used in this study was collected from Mottankurichi (Dharmapuri District). The collected biomass was washed with tap water several times to remove dirt and sand particles and washed a few times with distilled water and made them dry under sunlight for 3 days. Dry Ixora Coccinea leaves (ICL) were crushed into powder and sieved to 400micron particle size. It was then preserved in airtight containers for further use.

\section{Preparation of Dye Solution}

The dye RY-14, in commercial purity, was used without purification. The dye stock solutions were prepared by dissolving accurately weighed dye in the distilled water to the concentration of $1000 \mathrm{mg} / \mathrm{L}$. The experimental solutions were obtained by diluting the dye stock solutions in accurate proportions to different initial concentrations.

\section{Batch Experiments}

Batch experiments were conducted in stoppered reagent bottles of $250 \mathrm{~mL}$ capacity, which were provided with glass caps, $100 \mathrm{~mL}$ of different concentration of dye solutions under investigation was taken in each stoppered reagent bottles. After the addition of biomass, the stoppered reagent glass bottles were equilibrated for 4 hours using a rotary mechanical shaker. The initial $\mathrm{pH}$ values of the solutions were previously adjusted with $0.1 \mathrm{~N}$ sodium hydroxide or hydrochloric acid using a $\mathrm{pH}$ meter. Then the solutions were filtered and adsorbent of the filtrates was measured using UV visible spectrophotometer. Batch experiments were conducted for maximum biosorption of dye ions through the following studies: (i.) Effect of Sorption Dose, (ii.) Effect of Contact Time, (iii.) Effect of pH, (iv.) Adsorption Isotherm, (v.) Adsorption Kinetics

\section{RESULTS AND DISCUSSION}

\section{Effect of Sorbent Dose}

The effects of sorbent dose on the removal of RY-14 dye are shown in Fig-1. As the sorbent dose was increased over the range of 0.1-1.9 $\mathrm{g} / \mathrm{L}$, the percentage of dyes sorbed increased gradually ${ }^{4}$. The adsorption of dyes increased from 21.67 to $78.07 \%$. Increased surface area and presence of adsorption site make the dye to remove easily as the sorbent dose is increased ${ }^{15}$. Biomass dose of $1.9 \mathrm{gms}$ is required for maximum dye adsorption. Hence in all the further studies, the optimum weight of $1.9 \mathrm{gm}$. of biomass dose was maintained.

Table-1: Effect of Biomass Dose (Size 400 micron)

\begin{tabular}{c|c|c}
\hline S. No. & Biomass Dose & $\%$ of Dye Removal \\
\hline 1 & 0.1 & 21.67 \\
\hline 2 & 0.3 & 23.24 \\
\hline 3 & 0.5 & 26.87 \\
\hline 4 & 0.7 & 33.97 \\
\hline \multicolumn{2}{|c}{1416}
\end{tabular}


RASĀYAN J. Chem.

Vol. 11 | No. 4 |1415 - 1422| October - December | 2018

\begin{tabular}{c|c|c}
\hline 5 & 0.9 & 44.27 \\
\hline 6 & 1.1 & 54.93 \\
\hline 7 & 1.3 & 62.88 \\
\hline 8 & 1.5 & 70.46 \\
\hline 9 & 1.7 & 75.01 \\
\hline 10 & 1.9 & 78.07 \\
\hline
\end{tabular}

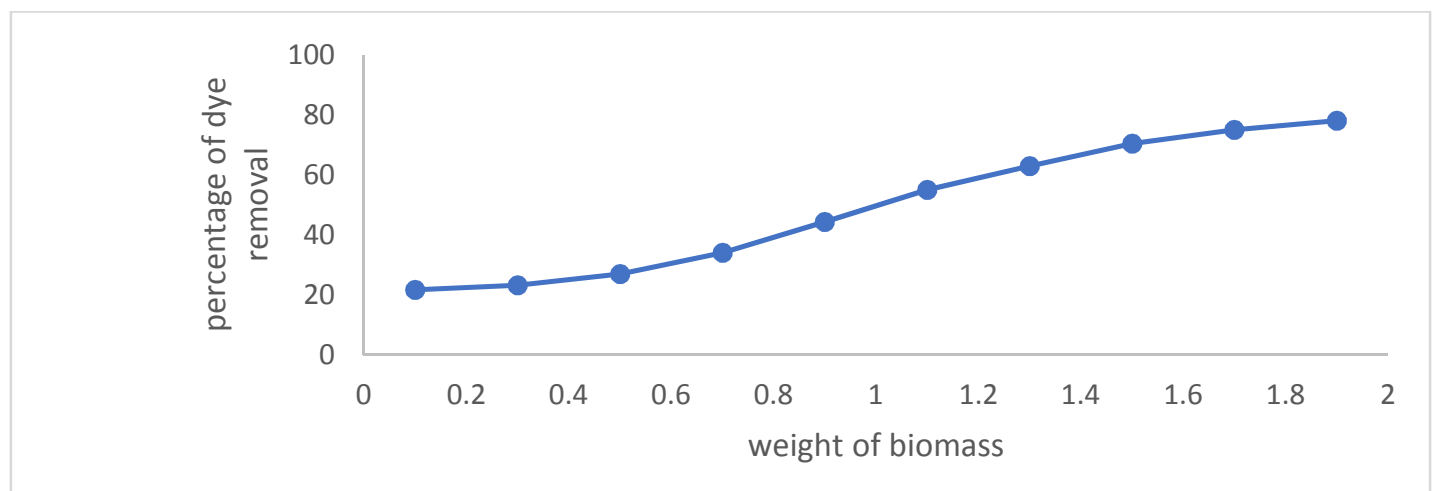

Fig.-1: Effect of Sorbent Dose on Adsorption of RY -14 by Ixora coccinea Leaves Powder (ICLP) (Dye Concentration: $100 \mathrm{mg} / \mathrm{L}$; Particle Size: $400 \mu$ Contact Time: 4 h).

\section{Effect of Contact Time}

The effect of contact time was studied in the range of $10-240$ minutes in $100 \mathrm{mg} / \mathrm{L}$ initial dye concentration with an adsorbent dose of $1 \mathrm{~g} / 100 \mathrm{~mL}$. From Fig.-2. it can be observed that the maximum percentage of removal of dye was achieved at 240 minutes after which the removal almost reached a constant ${ }^{16}$.Hence an equilibrium time of 240 minutes was considered for all further studies.

Table-2: Effect of Contact Time

\begin{tabular}{c|c|c}
\hline S. No. & Time(Min) & \% of Dye Removal \\
\hline 1 & 10 & 28.68 \\
\hline 2 & 20 & 30.79 \\
\hline 3 & 30 & 33.63 \\
\hline 4 & 60 & 40.34 \\
\hline 5 & 90 & 45.36 \\
\hline 6 & 120 & 50.01 \\
\hline 7 & 150 & 55.61 \\
\hline 8 & 180 & 62.08 \\
\hline 9 & 210 & 67.20 \\
\hline 10 & 240 & 72.38 \\
\hline
\end{tabular}

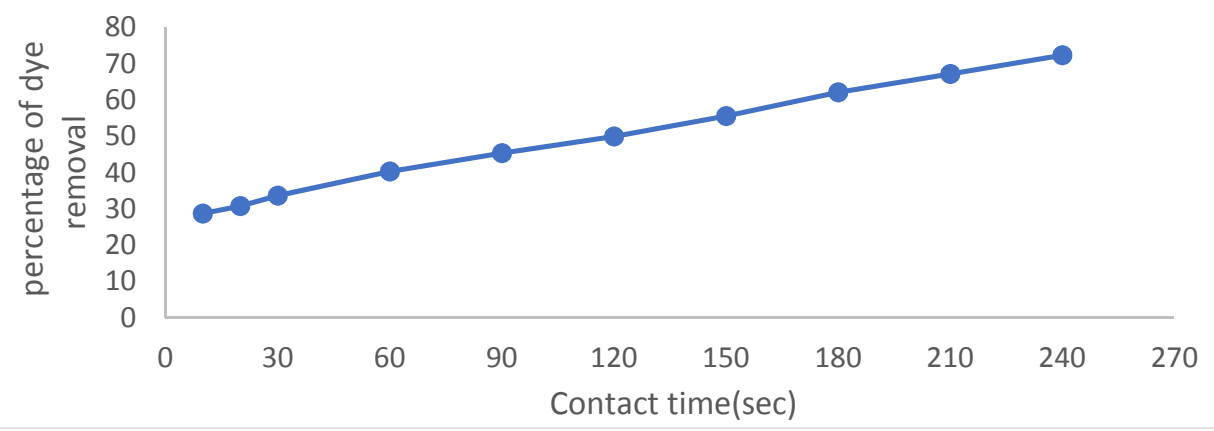

Fig.- 2: Influence of Dye Concentration on Adsorption of RY-14 by Ixora coccinea Leaves Powder (Sorbent Dose: $100 \mathrm{mg} / \mathrm{L}$; Particle Size: $400 \mu$, Contact Time: 4h). 


\section{Effect of pH}

The effect of initial $\mathrm{pH}$ on adsorption percentages of dyes was investigated over a range of $\mathrm{pH}$ values from 2 to 10. As given in Fig.-3. the maximum dye removal ratios were at the initial $\mathrm{pH}$ 2.The optimum $\mathrm{pH}$ value of the adsorbent is in good agreement with the values given in literature such as native strains, clay, bentonite ${ }^{17-19}$. This is due to high electrostatic attraction between the positive charged(high concentrations of $\mathrm{H}^{+}$) surface of the adsorbents and dye. When the $\mathrm{pH}$ is increased; the adsorption rate gets decreases and there is an increase in electrostatic repulsion ${ }^{8}$.

Table-3: Effect of $\mathrm{pH}$

\begin{tabular}{c|c|c}
\hline S. No. & $\mathrm{pH}$ & \% of Dye Removal \\
\hline 1 & 2 & 81.08 \\
\hline 2 & 3 & 72.38 \\
\hline 3 & 4 & 68.72 \\
\hline 4 & 5 & 67.31 \\
\hline 5 & 6 & 64.00 \\
\hline 6 & 7 & 49.91 \\
\hline 7 & 8 & 47.12 \\
\hline 8 & 9 & 44.07 \\
\hline 9 & 10 & 33.83 \\
\hline
\end{tabular}

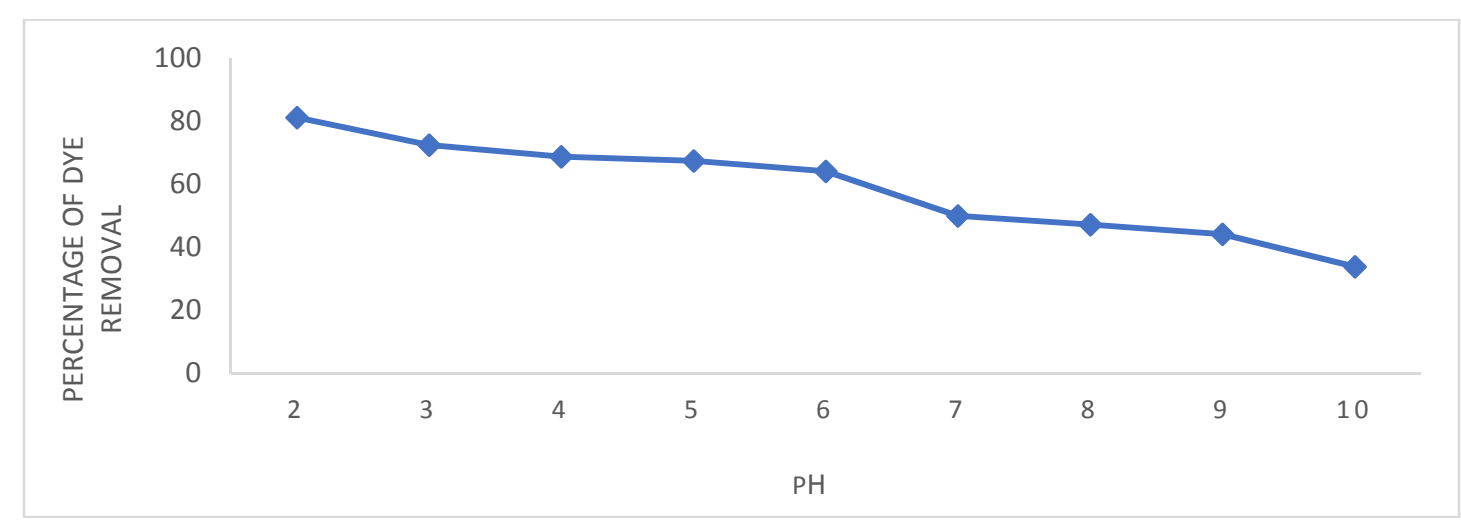

Fig.-3:Effect of Initial pH on Adsorption of RY-14 by Ixora coccinea Leaves Powder (Dye Concentration: 100 mg/L; Sorbent Dose: 1 g/L; Particle Size: $400 \mu$, Contact Time: 4 h; Temperature 300 K).

\section{Adsorption Isotherm}

Removal of organic pollutants can be well understood by the interaction between adsorbent and adsorbate and they are modeled by using Adsorption isotherms ${ }^{4}$. Isotherms are characterized by specific constants that express the surface properties and affinity of adsorbent towards the adsorbent pollutant ${ }^{20}$.Adsorption isotherm experiment was conducted by taking various amounts of adsorbents, ranging from 0.1 to $1.9 \mathrm{~g} / \mathrm{L}$ in various, reagent glass bottles. Different amounts of adsorbents were added to each case of $100 \mathrm{mg} / \mathrm{L}$ dye solution prepared in our laboratory. After an equilibration period of four hours absorbance of the supernatant clear liquid is determined spectrophotometrically at $375 \mathrm{~nm}$. The amount of dye adsorbed was calculated using the graph. The applicability of the isotherms was judged from the values of the correlation coefficient. Table- 4 shows that the $\mathrm{R}^{2}$ for Freundlich isotherm is closer to unity than that of Langmuir and Temkin isotherms.

Table-4: Correlation Coefficients $\left(\mathrm{R}^{2}\right)$ of Langmuir, Freundlich and Temkin Isotherm models

\begin{tabular}{c|c}
\hline Models & $\mathrm{R}^{2}$ \\
\hline Langmuir & 0.7857 \\
\hline Freundlich & 0.8771 \\
\hline Temkin & 0.7852 \\
\hline \multicolumn{2}{|c}{1418}
\end{tabular}




\section{Langmuir Adsorption Isotherm}

According to Langmuir monolayer adsorption was assumed to take place in all of the sites with equal energies and with surface homogeneity ${ }^{21}$.Langmuir adsorption isotherm is expressed by equation (1).

$$
\frac{\mathrm{x}}{\mathrm{m}}=\frac{\mathrm{a} \cdot \mathrm{b} \cdot \mathrm{Ce}}{1+\mathrm{b} \cdot \mathrm{Ce}}
$$

Where $\mathrm{x}=$ amount of dye adsorbed at equilibrium state, $\mathrm{m}=$ weight of adsorbent used, $\mathrm{Ce}=$ the equilibrium concentration of dye remaining, $a=$ constant, $b=$ Langmuir parameter

The equilibrium data of the removal of the dye concentration by adsorption source, i.e., ICLP have been correlated with Langmuir isotherm. The above equation (1) can be rearranged as,

$$
\frac{\mathrm{Ce}}{\mathrm{x} / \mathrm{m}}=\frac{1}{\mathrm{ab}}+\frac{1}{\mathrm{a}} \mathrm{Ce}
$$

The essential characteristics of ' $a$ ' and ' $b$ ' are expressed as follows:

$\mathrm{b}=$ sorption intensity, $\mathrm{a}=$ adsorption capacity

A linear plot was obtained when In Ce was plotted with $\mathrm{x} / \mathrm{m}$. This indicates that for the present system Langmuir model can be applied.The correlation coefficient $\mathrm{R}^{2}$ value for the RY-14 dye is obtained as 0.7857 .

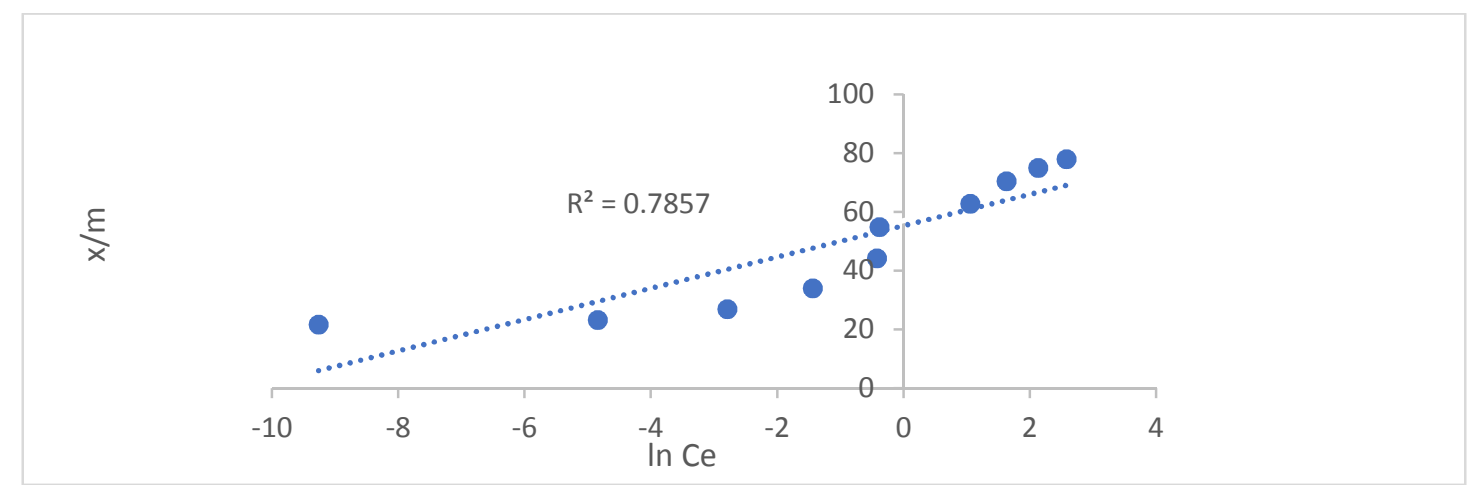

Fig.-4: Langmuir Plot for the Adsorption of Reactive Yellow-14 Dye

\section{Freundlich Adsorption Isotherm}

Adsorption data were modeled with the help of Freundlich adsorption isotherm. Vacant sites with distant energies and a heterogeneous absorbing surface were estimated by the Freundlich isotherm ${ }^{7}$. The Freundlich adsorption isotherm equation can be expressed as:

$\log \mathrm{x} / \mathrm{m}=\log \mathrm{K}+1 / \mathrm{n} \log \mathrm{Ce}$

Where $\mathrm{x}=$ amount of dye ion adsorbed $(\mathrm{mg}), \mathrm{m}=$ weight of adsorbent used $(\mathrm{mg}), \mathrm{Ce}=$ equilibrium dye concentration and $\mathrm{K}, 1 / \mathrm{n}=$ constant.

A plot of $\log \mathrm{x} / \mathrm{m}$ vs. $\log$ Ce was shown. The straight line nature of the graph indicates the monolayer formation and fitted with Freundlich adsorption isotherm ${ }^{14}$.

The parameter $R^{2}$ predicts that the type of isotherm could be irreversible $\left(R^{2}=0\right)$, favorable $\left(0<R^{2}<1\right)$ or unfavorable $\left(\mathrm{R}^{2}>1\right)$. The applicability of the linear form of the Freundlich model to ICLP was proved by the high correlation coefficients $\mathrm{R}^{2}>0.8771$. Results show that removal of RY-14 with ICLP fits Freundlich model better than Langmuir adsorption data.

\section{Temkin Isotherm}

The equilibrium data was further applied to the Temkin isotherm model. Indirect biosorbent-biosorbate interaction has been considered by Temkin model. It shows there is a linear decrease in the heat of biosorption for dye molecules ${ }^{19,22}$. The plot of $\mathrm{x} / \mathrm{m}$ versus $\log$ Ce for RY-14 adsorption on ICLP is 
presented in Fig.-6. It can be seen from the figure that the $\mathrm{R}^{2}$ value for the adsorption is 0.7852 which is less than the other two model.

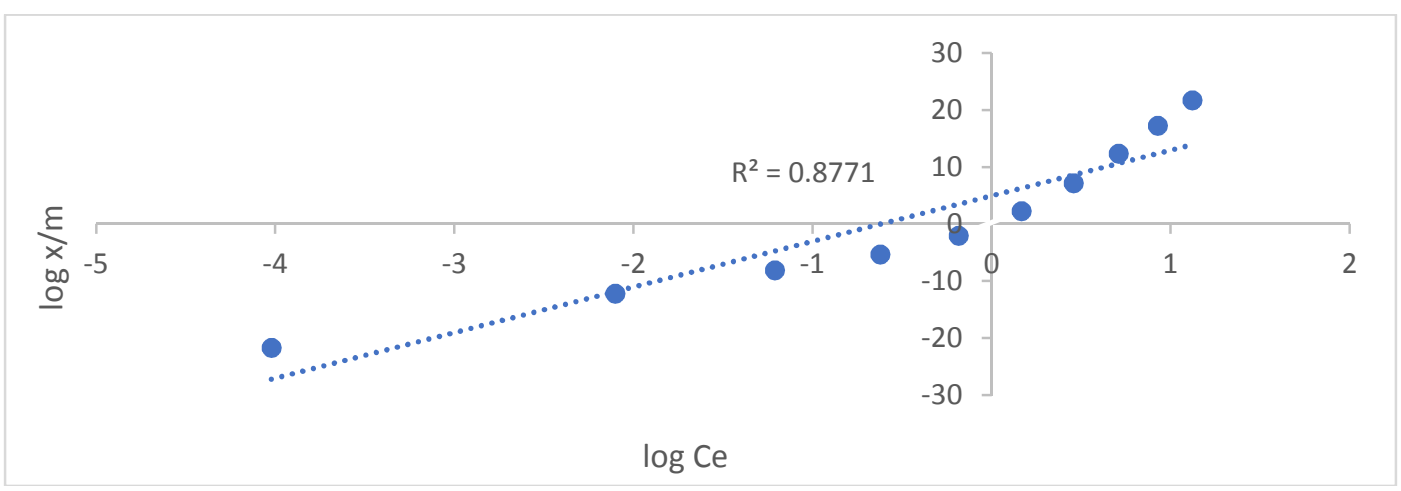

Fig.-5: Freundlich Plot for the Adsorption of Reactive Yellow-14 Dye

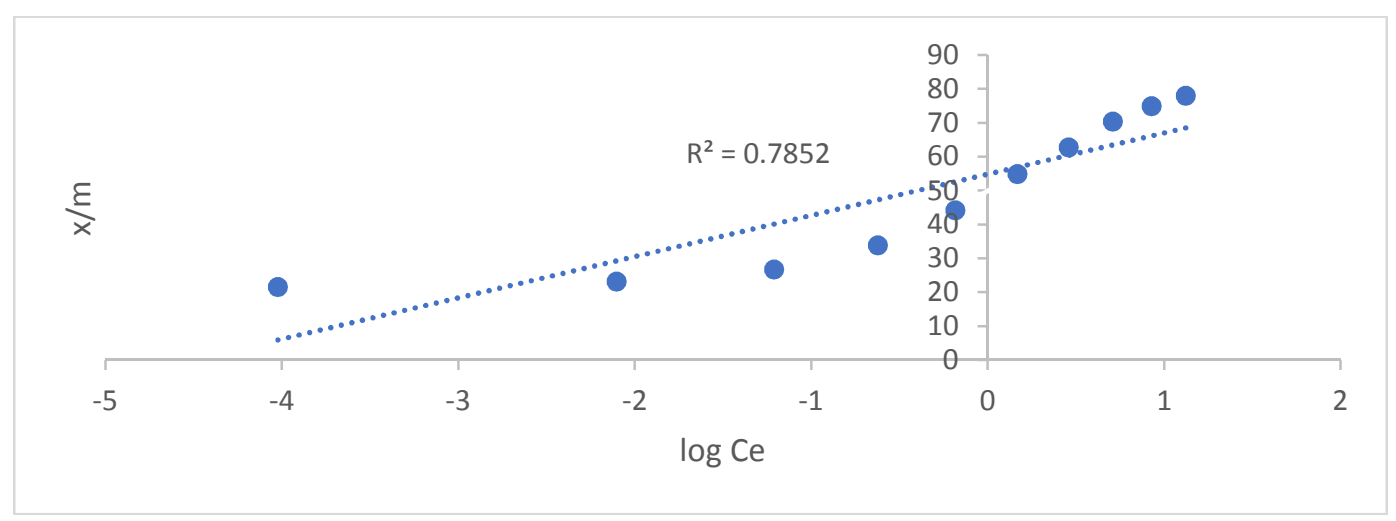

\section{Kinetics of Adsorption}

Fig.-6:Temkin Plot for the Adsorption of Reactive Yellow-14 Dye

In this experiment, $100 \mathrm{ml}$ of a dye solution with an initial concentration of 30, 40, 50, $60 \mathrm{ppm}$ have treated with $1 \mathrm{~g}$ of Biomass and equilibrated for 20 minutes interval in the range of 20 to 120 minutes with constant stirring. The residual dye concentration after the equilibration period was measured spectrophotometrically. The concentration of dye remaining in the solution is plotted with time vs equilibration period and was shown in Fig.-7. The Kinetic figure suggests that the dyes were adsorbed very rapidly and maximum adsorption was virtually completed within two hours.

\section{Rate Constant Studies}

The Kinetic equation of first order 1 is given by $\ln (1-\mathrm{ut})=-\mathrm{kt}$

Were Ut $=\frac{C A(0)-C A(t)}{C A(0)-C A(e)}$

Where CA $(0)=$ initial concentration CA $(\mathrm{t})=$ concentration at time ' $\mathrm{t}$ ' and $\mathrm{CA}(\mathrm{e})=$ equilibrium dye concentration for first order reaction.

The rate constant plot $\log (1-\mathrm{u}(\mathrm{t}))$ vs. contact time is shown in Fig.-8. The rate constant (K1) of the reaction is obtained from the slope of the plot.The straight line nature of the graph indicates that the reaction follows first order Kinetics.

\section{Scanning Electron Microscopy}

Figure-9 shows the SEM micrograph of ICLP samples before dye adsorption. It shows ICLP possesses rough surface morphology with well-defined pores of different sizes. It can be noted that ICLP has a heterogeneous surface with enough number of pores and cavities that acts as suitable binding sites for adsorption of RY-14 dye ${ }^{13}$. 
RASĀYAN J. Chem.

Vol. 11 | No. 4 |1415 - 1422| October - December | 2018

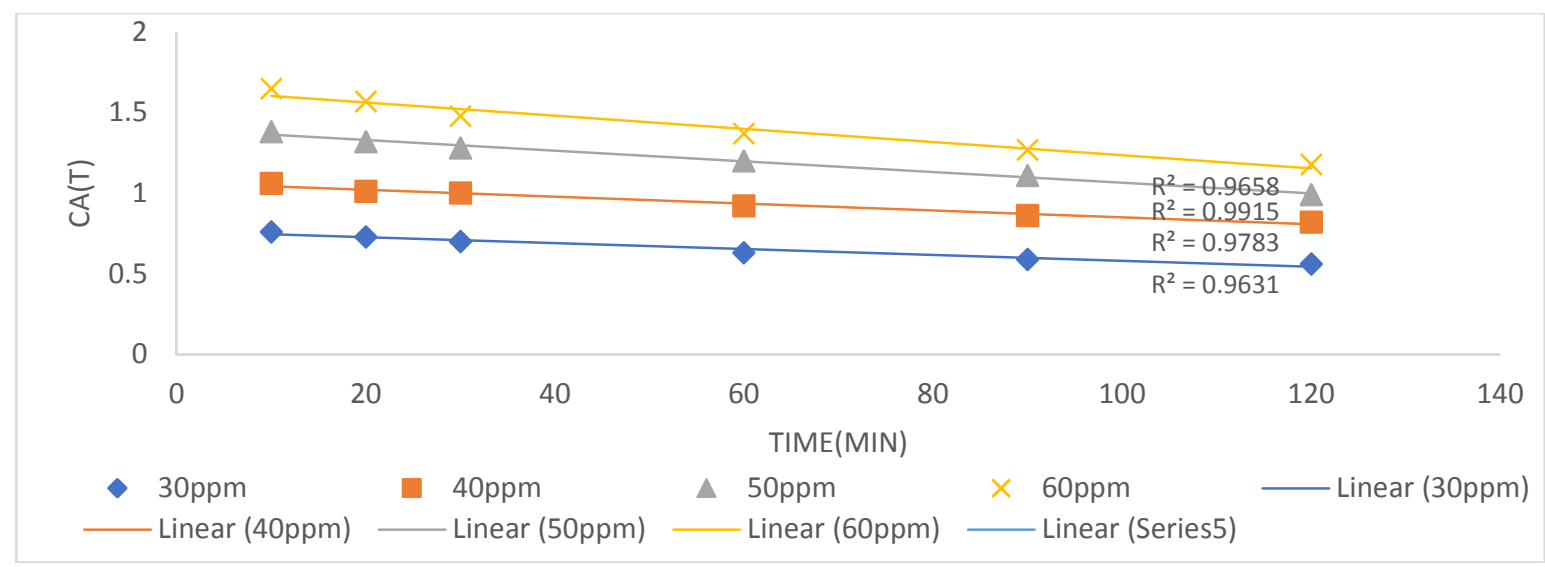

Fig.-7: Plot of Residual Dye Vs Contact Time

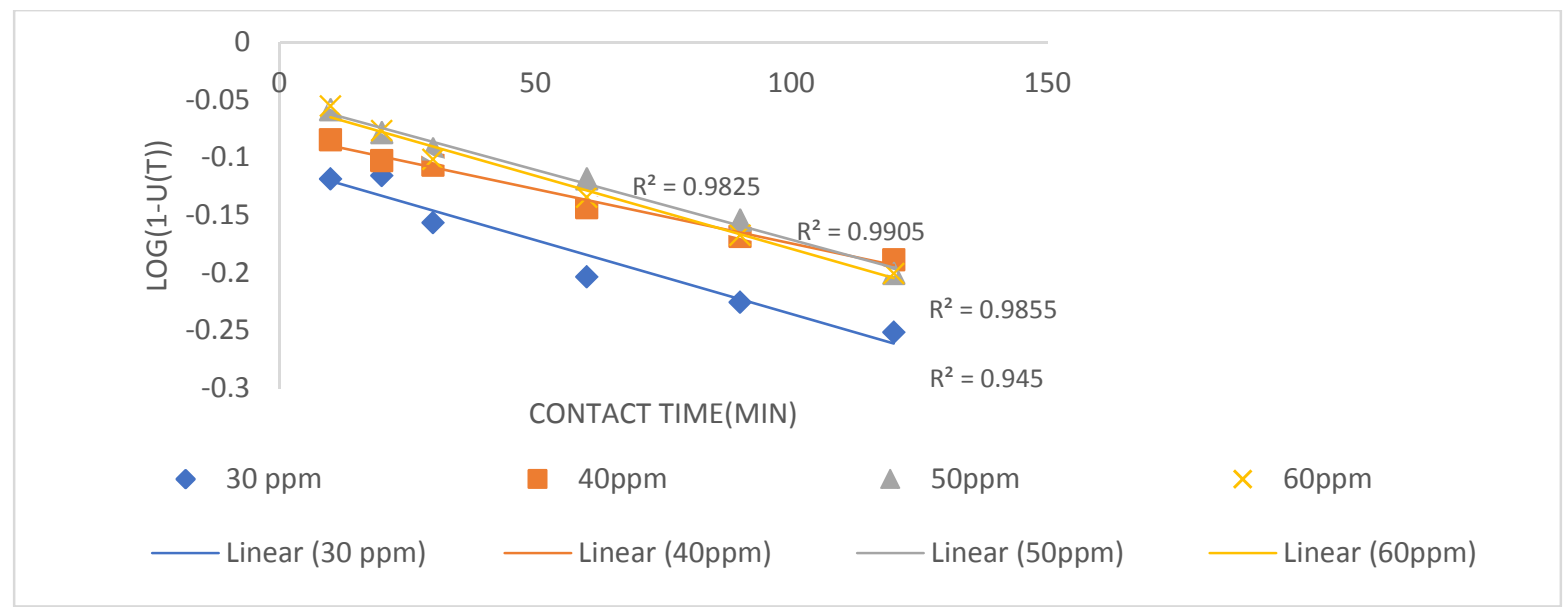

Fig.-8: Plot of $\log 1-\mathrm{u}(\mathrm{t})$ Vs Contact Time
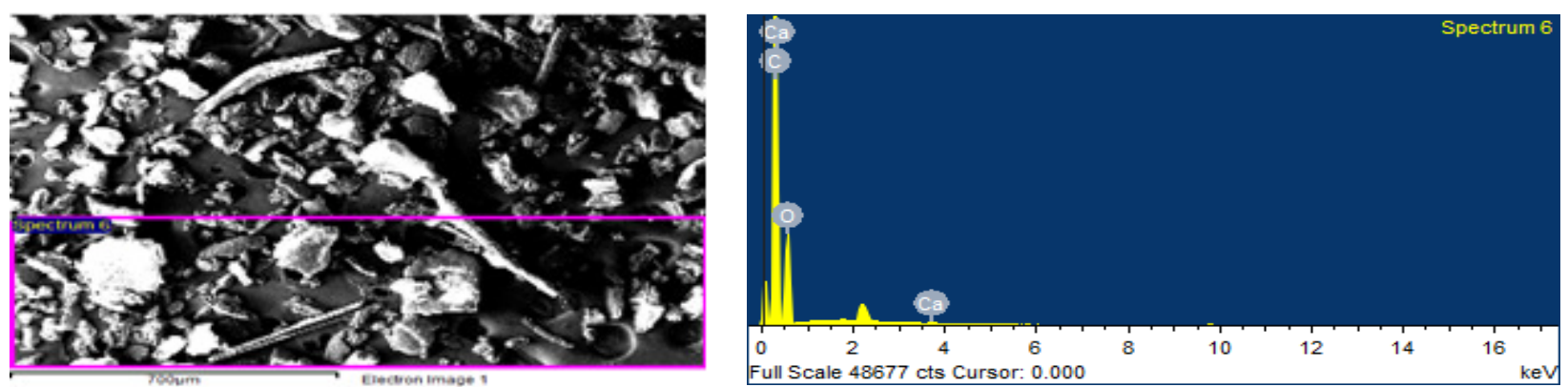

Fig.-9 : SEM Micrograph of ICLP $(700 \mu \mathrm{m})$ Before Adsorption

\section{CONCLUSION}

This study shows that ICLP could be used to Remove RY-14 dye from aqueous solution.The optimal $\mathrm{pH}$ was observed at2.As sorbent dose was increased, the percentages of dyes sorbed were also increased.The adsorption equilibrium was reached at about 4 hours. The isothermal data fit the Freundlich model.The adsorption process followed the pseudo-first-order rate kinetics.

\section{REFERENCES}

1. H. Revathi, T. Murugan and R. Sharmila Devi, International Journal of Current Engineering and Technology.,7, 958(2017).

2. T. Murugan, and A. Ganapathy, International Journal of Hazardous Material., 1, 1(2012). 
3. Mahalakshmi Mathivanan and Saranaathan S.E, Rasayan Journal of Chemistry,11, 877 (2018), DOI: 10.37188/RJC.2018.1122086.

4. Indira Khatod, International Journal of ChemTech Research., 5, 2, 572(2013).

5. Puthiya Veetil Nidheesh, Rajan Gandhimathi, Sreekrishnaperumal Thanga Ramesh and Tangappan Sarasvathy Anantha Singh, Journal of Urban and Environmental Engineering.,6, 18(2012), DOI: 10.4090/juee.2012.v6n1.018029.

6. Raffiea Baseri, P.N. Palanisamy and P. Sivakumar, E-Journal of Chemistry., 9, 1122(2012), DOI: 10.1155/2012/603196.

7. P. Pallavi, P. King and Y. Prasanna Kumar, Rasayan Journal of Chemistry,11, 203(2018), DOI:10.7324/RJC.2018.1111971.

8. Veeramalini J.B, Sravanakumar. K and Joshua Amarnath. D, International Journal of Science , Environment and Technology., 1, 56(2012).

9. Khalid M. Mousa, Alaa H. Taha, Petroleum Science and Engineering., 2, 17(2017), DOI: 10.11648/j.pse.20170201.14.

10. Samiksha V. Ashtikar, Amruta D. Parkhi, Journal of Engineering Research and Applications., 4, 75(2014).

11. Snehal Yedurkar, Chandra Maurya, Prakash Mahanwar, Open Journal of Synthesis Theory and Application., 5, 1(2016), DOI: 10.4236/ojsta.2016.51001.

12. K. Venkata Ramana, K. Swarna Latha , K. Ravindranath and B. Hari Babu, Rasayan Journal of Chemistry, 10, 349(2017), DOI: 10.7324/RJC.2017.1021537.

13. T.Murugan and A. Ganapathi, International Journal of Research in Environmental Science and Technology., 2, 10(2012).

14. Yash Mishra, V. Sowmya and S. Shanthakumar, Journal of Urban and Environmental Engineering.,9, 102(2015), DOI: 10.4090/juee.2015.v9n2.102108.

15. Rajvir Kaur and Harpreet Kaur, Asian Journal of Chemistry, 29, 441(2017), DOI: 10.14233/ajchem.2017.20242.

16. Hosein Nadi, Mostafa Alizadeh, Morteza Ahmadabadi, Ahmad Reza Yari, Sara Hashemi, Research Centre for Environmental Pollutants., 1, 41(2012).

17. Lin SH, Juang RS., A Review. J Environ Manage., 90, 1336(2009), DOI:10.1016/j.jenvman.2008.09.003.

18. Shokoohi R, Vatanpoor V, Zarrabi M, Vatani A., E-Journal of Chem.,7, 65 (2010), DOI: 10.1155/2010/958073.

19. I.A.W.Tan, A.L.Ahmad, B.H.Hameed, Desalination, 225 (1-3), 13(2008).

20. W.Astuti,T.Sulistyaningsih and M.Makshola, Asian Journal of Chemistry, 29, 133(2017), DOI: 10.14233/ajchem.2017.20158.

21. Yantus A.B Neolaka, Eka B.S Kalla, Gusti A. Malelak, Nia K. Rukman, Ganden Supriyanto and Ni Nyoman Tri Puspaningsih, Rasayan Journal of Chemistry, 11, 494(2018), DOI: 10.37188/RJC.2018.1121994.

22. P.Ahuja, R.Gupta, R.K.Saxena, Process Biochem., 34, 218(2006).

[RJC-3054/2018] 